\title{
TNF- $\alpha$ Level in Saliva as Early Detection of Periodontitis to Prevent Theseverity of Preeclampsia in Pregnant Women
} \author{
Gofur ${ }^{4}$ \\ ${ }^{1}$ Doctoral Program of Medical Science, Faculty of Medicine - Universitas Brawijaya, Indonesia \\ ${ }^{2}$ Indonesian Health Collaboration and Innovation Institute, Indonesia \\ ${ }^{3}$ Dental Public Health, Faculty of Dental Medicine, Universitas Airlangga, Indonesia \\ ${ }^{4}$ Faculty of Dental Medicine, Universitas Airlangga, Indonesia
}

Nanda Rachmad Putra Gofur ${ }^{1}$, Achmad Zam Zam Aghasy², Aulia Ramadhani* and Aisyah Rachmadani Putri

Submission: July 25, 2020; Published: August 10, 2020

*Corresponding author: Aulia Ramadhani, Dental Public Health, Faculty of Dental Medicine, Universitas Airlangga, Indonesia

Abstarct

Introduction: Periodontitis is a chronic inflammation of periodontal tissue that is often found in the oral cavity. 20-50\% of the world's population experiences periodontitis. Pregnant women tend to experience higher alveolar bone resorption due to the changes in estrogen levels. Pregnant women with preeclampsia experience an increase in TNF- $\alpha$ compared to pregnant women in normal circumstances. TNF- $\alpha$ is a protein that can be used as a detection for tissue damage.

Objective: To know the role of TNF- $\alpha$ of saliva as an early detection of periodontitis to prevent the severity of preeclampsia in pregnant women.

Discussion: Periodontitis shows an increase in TNF- $\alpha$. The higher TNF- $\alpha$ level is found in pregnant women than in postpartum condition. TNF- $\alpha$ levels can worsen the condition of pregnant women due to more inflammation and tissue damage. In preeclampsia, high TNF- $\alpha$ levels can also increase the severity of the condition.

Conclusion: In Preeclampsia, there is an increase TNF- $\alpha$ levels which shows the tissue destruction. In pregnant women with periodontitis can make a worst condition to both the fetus and mother, especially in preeclampsia condition.

Keywords: TNF- $\alpha$; Periodontitis; Preeclampsia; Pregnancy; Hormones

\section{Introduction}

Periodontitis is a chronic inflammation of periodontal tissue that is often found in the oral cavity. Periodontitis can cause many things, from swelling of the gingiva and even tooth loss [1]. 1 This disease is often experienced by adults to old age. Individuals aged 65-74 years are more at risk for periodontitis. Sanz et al in [2] stated that $20-50 \%$ of the world's population experiences periodontitis. As in old age, women are more at risk of periodontitis than men. Hormonal changes in women can increase the risk of periodontal disease. Longitudinal studies conducted by Grodstein et al [3] showed that 42,171 women at their postmenopausal phase was receiving osteoporosis treatment used estrogen hormone which affected to the decrease of tooth loss.
Women with periodontitis are at risk with other inflammatory diseases which results to the tissue destruction. Women often experience hormonal changes, especially during pregnancy [4]. Pregnant women tend to experience higher alveolar bone resorption due to the changes in estrogen levels. Alveolar bone resorption is due to a decrease in bone density resulting in loss of attachment. This associated to the accumulation of pro-inflammatory cytokines [5].

Damage to excess tissue in the body can increase the accumulation of proinflammatory cytokines. In women, proinflammatory cytokines are more common. It can also increase the risk of preeclampsia in pregnant women. Pregnant women with preeclamp- 
sia experience an increase in TNF- $\alpha$ compared to pregnant women in normal circumstances [6].

Saliva is one of the tools to diagnose the inflammation in ora cavity. In saliva, contains host proteins such as enzymes, cytokines and immunoglobullins that can be markers of disease in oral cavity. TNF- $\alpha$ is a protein that can be used as a detection for tissue damage. One of the proinflammatory cytokines that increase when tissue inflammation occurs. Therefore, in this article, it has the objective that the TNF- $\alpha$ of saliva can be used as an early detection of periodontitis to prevent preeclampsia in pregnant women [7].

\section{Periodontitis}

Periodontitis is inflammation of the periodontal tissue. This disease occurs due to inflammation of the periodontal tissue caused by plaque. Plaque is an accumulation of bacteria and food scraps attached to the teeth. There are various bacteria that cause periodontitis, one of which is often encountered, namely A. Actinomycetemcomitans [8].

Elderly is more at risk of periodontitis because of the aging process which causes loss of attachment and decreased alveolar bone density. On radiographic examination, periodontitis shows a loss of lamina dura, some cases are accompanied by widening of the periodontal ligament and a decrease in alveolar crest. Patients with systemic disease have a high risk of periodontitis as in people with diabetes mellitus. In these patients experiencing microangiopathy which leads to periodontitis [9].

Periodontitis experienced by systemic sufferers can also make the systemic disease worse. That is because the occurrence of excessive inflammation causes a high accumulation of proinflammatory cytokines resulting in greater tissue damage. Tissue damage, especially this periodontal tissue can reduce a person's quality of life and can cause other problems in the oral cavity [10].

\section{Tumor Necrosis Factor- $a($ TNF- $\alpha)$}

TNF- $\alpha$ is a protein which include in the pro-inflammatory cytokines. These cytokines cause tissue damage. When the inflammatory process occurs, TNF- $\alpha$ TNF- $\alpha$ TNF- $\alpha$ levels will increase. This can be used as a marker of infection. TNF- $\alpha$ is the body's immune response. The level of TNF- $\alpha$ is affected by the severity of a disease, so the more severe a disease, the greater the damaged tissue. TNF- $\alpha$ can be used as a response to bacteria that contain lipopolysaccharides. This mechanism results in leukocyte accumulated and vascular permeability facilitated by the expression of selectin and adhesion stimulation. Macrophage which can induce the angiogenesis is also mediated by TNFa and has an important role in vascular proliferation which is the formation of periodontal granulation tissue. TNF- $\alpha$ triggers osteoclast activation which causes bone resorption.

TNF- $\alpha$ levels have become one of the "tools" for diagnosis. On examination, TNF- $\alpha$ levels can be seen through blood, saliva, or other body fluids such as GCF (Gingival Cravicular Fluid). In patients with periodontitis TNF- $\alpha$ levels found in GCF are higher than in normal people. Whereas in patients with periodontitis who have systemic disease, TNF- $\alpha$ is higher than in patients with periodontitis without systemic disease. This also happens to pregnant women. Pregnant women are also a risk factor for periodontitis [11].

\section{Preeclampsia}

The pathology of preeclampsia shows an imbalance of the immune system causing invasion of damaged trophoblasts. In the developmental process of the vascular placenta, cytotrophoblasts attack the uterine spiral arteries which replace the endothelial lining. During the second trimester, the uterine spiral arteries are limited by cytotrophoblasts. Regeneration of the spiral arteries results in a drastic increase in blood supply to the developing fetus. Thus, if failure of trophoblast invasion results in a decrease in uterine perfusion pressure and placental ischemia [12].

Ischemic placenta can induce proinflammatory cytokines which can contribute to mediating the widespread spread of endothelial damage to preeclampsia [13]. The absence of semiallogenic fetal rejection by the activated immune system of the mother is a true immunological paradox that is not yet fully understood. Preeclampsia and recurrent abortion are considered by the majority of obstetricians as a result of changes in the process of maintaining an physiological immune pregnancy. At the first interface level, leukocyte infiltration and increased production of proinflammatory cytokines (IL-12, IL-15, IL-18, INF-y) are found, while at a systemic level, in pregnancy compared to non-pregnant. status, leukocytosis and leukocyte activation, endothelial complement activation, coagulation and platelet activation are seen, accompanied by increased synthesis of proinflammatory cytokines (IL-12, IL-6, IL-18, IL-8, TNF- $\alpha$, INF-y). [12,13].

\section{Pregnancy}

In pregnant women, often found the hormon changes. It lead to the whanges in salivary factors hich can affect pregnant women [14]. Several studies have reported, in 2nd and 3rd trimester there is an increase of the prevalence and severity of gingival inflammation and can back to the normal during postpartum. It occurs due to the immune system and the oral biofilms changes.This mechanism can lead the bad oral health and the higher tissue destruction [15].

In assessing the role of cytokine oral fluid levels in the higher prevalence of gingivitis in pregnancy, reported higher levels of cytokin proinflammatory such as interleukin 1 beta (IL-1 $\beta$ ) in gingival crevicular fluid in pregnant women compared to non-pregnant women. Also, pregnant women show a significant reduction in crevicular fluid levels of gingival IL- $1 \beta$ three months postpartum $[16,17]$. Salivary defense mechanisms are numerous and include locally produced and systemic cytokines, immunoglobulins, lysozyme, mucin, and various antimicrobial proteins (AMP). AMP, a family of antimicrobial agents, has a role as a major component of 
the innate defense mechanism. AMPs have been identified in most physiological fluids and in open environments, such as the mouth, where they play an important role in the balance between health and disease. There is an increase in periodontal inflammation has been reported in pregnant women and the correlation with the role of cytokines and antimicrobial proteins. Previous studies have reported the changes levels of TNF- $\alpha$ in crevicular fluid of gingival, serum, gingival tissue, and plasma of chronic non-pregnant periodontitis patients also. Thus, evaluation of salivary cytokines and antimicrobial proteins throughout saliva can provide a significant tool for assessing the immunological status associated with periodontal inflammation caused by pregnancy [18].

\section{Discussion}

Problems in the oral cavity are associated with pregnancy. Disease in periodontal tissue has a large impact on the people. Periodontitis has been reported to be closely related to pregnancy. Pregnant women in the first trimester to the third often experience periodontitis [10]. Periodontitis in pregnant women is more severe when compared to not pregnant. In pregnant women, there is greater tissue damage. Previous research has shown that pregnant women have poor oral health, this can also worsen the periodontal condition. Hormonal imbalance that is owned by pregnant women is thought to be a cause of periodontitis. The hormones that experience changes during pregnancy are progesterone, estrogen and human chorionic gonadotropin. Esrogen decline is experienced by pregnant women in the first to third trimester. Estrogen is thought to have a role in periodontitis $[10,17]$.

Periodontitis itself shows an increase in TNF- $\alpha$. TNF- $\alpha$ appears as the body's immune response to infection. Infection by bacteria in periodontal tissue begins with the formation of plaque and then becomes calculus which results in gingival inflammation. Gingival inflammation is left and exacerbated by the accumulation of more bacteria. Several studies have shown the higher TNF- $\alpha$ level is found in pregnant women than in postpartum condition. TNF- $\alpha$ levels can worsen the condition of pregnant women due to more inflammation and tissue damage. TNF- $\alpha$ cause the oxidative destruction in mitochondria which induces oxidizing fre radicals and formation of peroxides that make a damages in endothelial cells. Periodontitis often found in pregnant women [19,20].

In preeclampsia, high TNF- $\alpha$ levels can also increase the severity of the condition, although there is no definitive study of higher TNF- $\alpha$ levels that can cause preeclampsia severity. However, based on existing literaure shows that high TNF- $\alpha$ can worsen a pathological condition in the body. These condition can increase the severity of preeclampsia $[19,21]$.

\section{Conclusion}

Both TNF- $\alpha$ levels in saliva and in blood can be used as an early detection in the tissue destruction which lead to the severity of periodontitis. In Preeclampsia, there is an increase TNF- $\alpha$ levels which shows the tissue destruction. In pregnant women with peri- odontitis can make a worst condition to both the fetus and mother.

\section{References}

1. de Pablo P, Chapple IL, Buckley CD, Dietrich T (2009) Periodontitis in systemic rheumatic diseases. Nat Rev Rheumatol 5(4): 218-224.

2. Sanz M, D’Aiuto F, Deanfield J, Fernandez-Avilés F (2010) European workshop in periodontal health and cardiovascular disease-scientific evidence on the association between periodontal and cardiovascular diseases: A review of the literature. Eur Heart J Suppl 12 (Suppl B): B3-B12.

3. Grodstein F, Colditz GA, Stampfer MJ (1996) Post-menopausal hormone use and tooth loss: A prospective study. J Am Dent Assoc 127(3): 370-377.

4. Chaloupka P, Korec `ko V, Turek J, Merglova' V (2014) Oral health status of women with normal and high-risk pregnancies. Ceska Gynekol 79(1): 29-33.

5. Lasisi T], Abdus-salam RA (2018) Pregnancy-induced periodontal inflammation: Influence of salivary cytokines and antimicrobial proteins. Saudi Dent J 30(4): 306-311.

6. Udenze I, Amadi C, Awolola N, Makwe CC (2015) The role of cytokines as inflammatory mediators in preeclampsia. Pan Afr Med J 20: 219.

7. Varghese SS, Thomas H, Jayakumar ND, Sankari M, Lakshmanan R, et al. (2015) Estimation of salivary tumor necrosis factor-alpha in chronic and aggressive periodontitis patients. Contemp Clin Dent 6(Suppl 1): S152-156.

8. Borrell LN et al. (2007) Diabetes in the dental office: using NHANES III to estimate the probability of undiagnosed disease. J Periodontal Res 42(5): 559-565.

9. Graziani F, Gennai S, Solini A, Petrini M (2018) A systematic review and meta-analysis of epidemiologic observational evidence on the effect of periodontitis on diabetes an update of the EFP-AAP review. J Clin Periodontol 45(2): 167-187.

10. Zhu J, Guo B, Fu M, Guo W, Yuan Y, et al. (2016) Interleukin-6- 174G/C polymorphism contributes to periodontitis susceptibility: an updated meta-analysis of 21 case-control studies. Disease Markers.

11. Gomes MS, Blattner TC, Sant'Ana Filho M, Grecca FS, Hugo FN, et al. (2013) Can apical periodontitis modify systemic levels of inflammatory markers? a systematic review and meta-analysis. J Endod 39(10): 1205-1217.

12. Reslan OM, Khalil RA (2010) Molecular and vascular targets in the pathogenesis and management of the hypertension associated with preeclampsia. Cardiovasc Hematol Agents Med Chem 8(4): 204-226.

13. Lai Z, Kalkunte S, Sharma S (2011) A Critical Role of Interleukin-10 in Modulating Hypoxia-Induced Preeclampsia-Like Disease in Mice. Hypertension 57(3): 505-514.

14. Wegmann TG, Lin H, Guilbert L, Mosmann TR (1993) Bidirectional cytokine interactions in the maternal-fetal relationship: is successful pregnancy a Th2 phenomenon? Immunol Today 14(7): 353-356.

15. Chaloupka P, Korec`ko V, Turek J, Merglova' V (2014) Oral health status of women with normal and high-risk pregnancies. Ceska Gynekol 79(1): 29-33.

16. Figuero E, Carrillo-de-Albornoz A, Martı́n C, Tobı́as A, Herrera D, et al. ( 2013) Effect of pregnancy on gingival inflammation in systemically healthy women: a systematic review. J Clin Periodontol 40(5): 457-473.

17. Jonsson R, Howland BE, Bowden GHW (1988) Relationships between periodontal health, salivary steroids, and Bacteroides intermedius in males, pregnant and non-pregnant women. J Dent Res 67(8): 10621069. 
18. van 't Hof W, Veerman EC, Nieuw Amerongen AV, Ligtenberg AJ (2014) Antimicrobial defense systems in saliva. Monogr Oral Sci 24: 40-51.

19. Marlin SD, Springer TA (1987) Purified intercellular adhesion molecule-1 (ICAM-1) is a ligand for lymphocyte function-associated antigen 1(LFA-1). Cell 51(5): 813-819.
20. Conrad KP, Miles TM, Benyo DF (1998) Circulating levels of immunoreactive cytokines in women with preeclampsia. Am J Reprod Immunol 40(2): 102-111.

21. Abbus A, Lichtman A (2005) Cellular and Molecular Immunology. General Properties of the Immune Response, Cells and Tissues of the Immune System. Elsevier, p. 189-215.

\section{Your next submission with Juniper Publishers will reach you the below assets}

- Quality Editorial service

- Swift Peer Review

- Reprints availability

- E-prints Service

- Manuscript Podcast for convenient understanding

- Global attainment for your research

- Manuscript accessibility in different formats ( Pdf, E-pub, Full Tsext, Audio)

- Unceasing customer service

Track the below URL for one-step submission https://juniperpublishers.com/online-submission.php 